\section{BRAZIULIAN JOURNAL \\ OF MIEDICAL AND BIOLOGICAL RESFARCH}

www.bjournal.com.br
ISSN 0100-879X

Volume 43 (02) 124-225 February 2010

BIOMEDICAL SCIENCES

AND

CLINICAL INVESTIGATION

Braz J Med Biol Res, February 2010, Volume 43(2) 201-205

Lung hyperinflation stimulates the release of inflammatory mediators in spontaneously breathing subjects

L.M.S. Malbouisson, T.F. Szeles, L. Barbalho, C.O. Massoco, M.J.C. Carmona, C.R.R. Carvalho,

P. Pelosi and J.O.C. Auler Jr.

The Brazilian Journal of Medical and Biological Research is partially financed by
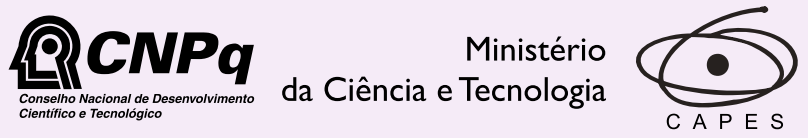

Ministério da Educação

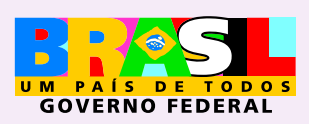

Institutional Sponsors 


\title{
Lung hyperinflation stimulates the release of inflammatory mediators in spontaneously breathing subjects
}

\author{
L.M.S. Malbouisson ${ }^{1}$, T.F. Szeles ${ }^{1}$, L. Barbalho ${ }^{1}$, C.O. Massoco ${ }^{1}$, \\ M.J.C. Carmona ${ }^{1}$, C.R.R. Carvalho ${ }^{2}$, P. Pelosi ${ }^{3}$ and J.O.C. Auler Jr. ${ }^{1}$ \\ ${ }^{1}$ Divisão de Anestesiologia, ${ }^{2}$ Divisão de Pneumologia, Hospital das Clínicas, Faculdade de Medicina, \\ Universidade de São Paulo, São Paulo, SP, Brasil \\ ${ }^{3}$ Dipartimento Ambiente, Salute e Sicurezza, Universita' degli Studi dell'Insubria, Varese, Italy
}

\begin{abstract}
Lung hyperinflation up to vital capacity is used to re-expand collapsed lung areas and to improve gas exchange during general anesthesia. However, it may induce inflammation in normal lungs. The objective of this study was to evaluate the effects of a lung hyperinflation maneuver (LHM) on plasma cytokine release in 10 healthy subjects (age: $26.1 \pm 1.2$ years, BMI: $23.8 \pm 3.6$ $\mathrm{kg} / \mathrm{m}^{2}$ ). LHM was performed applying continuous positive airway pressure (CPAP) with a face mask, increased by $3-\mathrm{cmH}_{2} \mathrm{O}$ steps up to $20 \mathrm{cmH}_{2} \mathrm{O}$ every 5 breaths. At CPAP $20 \mathrm{cmH}_{2} \mathrm{O}$, an inspiratory pressure of $20 \mathrm{cmH}_{2} \mathrm{O}$ above CPAP was applied, reaching an airway pressure of $40 \mathrm{cmH}_{2} \mathrm{O}$ for 10 breaths. CPAP was then decreased stepwise. Blood samples were collected before and 2 and $12 \mathrm{~h}$ after LHM. TNF- $\alpha$, IL-1 $\beta$, IL- 6 , IL-8, IL-10, and IL-12 were measured by flow cytometry. Lung hyperinflation

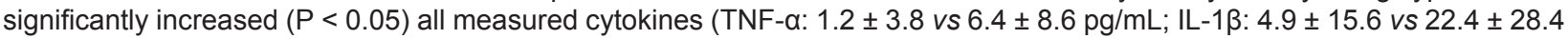
$\mathrm{pg} / \mathrm{mL}$; IL-6: $1.4 \pm 3.3$ vs $6.5 \pm 5.6 \mathrm{pg} / \mathrm{mL}$; IL-8: $13.2 \pm 8.8$ vs $33.4 \pm 26.4$ pg/mL; IL-10: $3.3 \pm 3.3$ vs $7.7 \pm 6.5 \mathrm{pg} / \mathrm{mL}$, and IL-12: $3.1 \pm 7.9$ vs $9 \pm 11.4 \mathrm{pg} / \mathrm{mL}$ ), which returned to basal levels $12 \mathrm{~h}$ later. A significant correlation was found between changes in pro- (IL-6) and anti-inflammatory (IL-10) cytokines $(r=0.89, \mathrm{P}=0.004)$. LHM-induced lung stretching was associated with an early inflammatory response in healthy spontaneously breathing subjects.
\end{abstract}

Key words: Lung hyperinflation; Ventilator-induced lung injury; Inflammation; Cytokines

\section{Introduction}

Pulmonary collapse is a frequent complication in sedated patients with either normal or injured lungs undergoing mechanical ventilation, decreasing respiratory system compliance and worsening gas exchange (1-4).

Lung hyperinflation maneuvers (LHM) used to expand lungs up to vital capacity by means of elevated inspiratory pressures have been shown to reopen collapsed lung regions and to improve pulmonary gas exchange (5-8). Despite these short-term beneficial effects on blood oxygenation and lung mechanics, a growing body of evidence from experimental and clinical studies has shown that overinflation-induced lung stretch may induce pulmonary inflammation with the release of cytokine and promote lung tissue injury (9-13). However, few data are available about the impact of lung hyperinflation maneuvers on pulmonary inflammatory response in spontaneously breathing healthy subjects, independently of the known harmful effects of mechanical ventilation $(14,15)$.

We hypothesize that, even in spontaneously breathing healthy subjects, respiratory maneuvers that promote lung over-distention would induce a pulmonary-generated inflammatory response and the release of cytokines into blood. The objective of the present study was to evaluate plasma cytokine behavior after an LHM applied to healthy spontaneously breathing subjects for a short period of time.

\section{Material and Methods}

After approval by the Institutional Ethics Committee of the Hospital das Clínicas of São Paulo University Medical School and obtaining written informed consent, 10 non-smoking spontaneously breathing healthy young adult volunteers were studied. None of the subjects had a history of lung disease, active lung or systemic infection,

Correspondence: J.O.C. Auler Jr., Programa de Pós-graduação e Pesquisa em Anestesiologia, InCor, HCFMUSP, Av. Dr. Enéas de Carvalho Aguiar, 44, 2ํandar, 05403-900 São Paulo, SP, Brasil. Fax: +55-11-3069-5367. E-mail: pg.anestesiologia@incor.usp.br 
drug-induced immunosuppression or underlying disease, or was currently using anti-inflammatory medications.

LHM was performed using a non-invasive ventilator (BiPAP Vision, Respironics Inc., USA) with a $21 \%$ inspiratory oxygen fraction during spontaneous quiet breathing. The subjects were comfortably seated on a chair and a total face mask (Respironics Inc.) was tightly adjusted to avoid air leaks. Five $\mathrm{cmH}_{2} \mathrm{O}$ of continuous positive airway pressure (CPAP) was first applied, and increased by $3 \mathrm{cmH}_{2} \mathrm{O}$ in a stepwise fashion every 5 breaths until reaching 20 $\mathrm{cmH}_{2} \mathrm{O}$. When $20 \mathrm{cmH}_{2} \mathrm{O}$ CPAP was reached, an additional inspiratory pressure of $20 \mathrm{cmH}_{2} \mathrm{O}$ above CPAP was set by using the pressure bi-level ventilation mode, reaching an end-inspiratory airway peak pressure of $40 \mathrm{cmH}_{2} \mathrm{O}$ during the successive 10 breaths. Thereafter, CPAP was decreased stepwise from 20 to $5 \mathrm{cmH}_{2} \mathrm{O}$ every 5 breaths by $3 \mathrm{cmH}_{2} \mathrm{O}$ steps. During the entire LHM procedure, the subjects were continuously monitored by electrocardioscopy and pulse oximetry while arterial pressure was recorded noninvasively at 1-min interval. After the end of the LHM, the subjects were carefully examined to exclude possible respiratory complications and control chest $\mathrm{X}$-ray plates were obtained. Venous blood samples were collected immediately before (baseline) and 2 and $12 \mathrm{~h}$ after the LHM.

Table 1. Antropometric data of the healthy subjects studied.

\begin{tabular}{cccccc}
\hline Subject & Gender & $\begin{array}{c}\text { Age } \\
(\text { years })\end{array}$ & $\begin{array}{c}\text { Weight } \\
(\mathrm{kg})\end{array}$ & $\begin{array}{c}\text { Height } \\
(\mathrm{m})\end{array}$ & $\begin{array}{c}\mathrm{BMI} \\
\left(\mathrm{kg} / \mathrm{m}^{2}\right)\end{array}$ \\
\hline 1 & $\mathrm{~F}$ & 25 & 52 & 1.64 & 19.3 \\
2 & $\mathrm{~F}$ & 26 & 56 & 1.63 & 21.1 \\
3 & $\mathrm{M}$ & 26 & 92 & 1.82 & 27.8 \\
4 & $\mathrm{M}$ & 27 & 88 & 1.87 & 25.2 \\
5 & $\mathrm{M}$ & 27 & 80 & 1.82 & 24.2 \\
6 & $\mathrm{~F}$ & 26 & 54 & 1.62 & 20.6 \\
7 & $\mathrm{~F}$ & 24 & 61 & 1.61 & 23.5 \\
8 & $\mathrm{~F}$ & 27 & 57 & 1.63 & 21.5 \\
9 & $\mathrm{~F}$ & 28 & 66 & 1.66 & 24.0 \\
10 & $\mathrm{M}$ & 25 & 104 & 1.83 & 31.1 \\
\hline
\end{tabular}

$\mathrm{BMI}=$ body mass index .

Table 2. Oximetric and hemodynamic data before and after lung hyperinflation.

\begin{tabular}{lcc}
\hline & Pre-LHM & Post-LHM \\
\hline Pulse oximetry (\%) & $97 \pm 1$ & $98 \pm 1^{*}$ \\
Heart rate (bpm) & $71 \pm 15$ & $70 \pm 13$ \\
Mean arterial pressure (mmHg) & $94 \pm 13$ & $88 \pm 9$ \\
\hline
\end{tabular}

LHM = lung hyperinflation maneuver. ${ }^{*} \mathrm{P}<0.05$ compared to preLHM (Wilcoxon paired test).
Immediately after sampling, 5-mL aliquots of venous blood containing EDTA were centrifuged at $1100 \mathrm{~g}$ for 3 min, and the plasma was aspirated and stored at $-70^{\circ} \mathrm{C}$. Simultaneous detection of multiple soluble analytes in a particle-based immunoassay was used to quantitatively measure interleukin (IL)-1 $\beta$, IL-6, IL-8, IL-10, IL-12, and tumor necrosis factor (TNF)- $\alpha$ protein levels in serum samples by a cytometric bead array (Human Inflammation Kit, BD Biosciences, Germany).

\section{Statistical analysis}

Statistical analysis was performed using the Sigmastat 3.0 statistical package. Heart rate and mean arterial pressure were compared before and immediately after LHM by the paired Student $t$-test. Peripheral oxygen saturation values were tested by the Wilcoxon paired test. Blood cytokine concentrations as a function of time were analyzed by one-way analysis of variance (ANOVA) for repeated measures followed by the Student-Newman-Keuls test for post hoc analysis when indicated. Correlations between cytokines were studied using linear regression and Pearson product-moment correlation coefficient. Data are reported as means $\pm S D$ and the level of significance was set at $P$ $<0.05$.

\section{Results}

Four male and 6 female healthy subjects with a mean age of $26.1 \pm 1.2$ years and mean body mass index of 23.8 $\pm 3.6 \mathrm{~kg} / \mathrm{m}^{2}$ were included in the study (Table 1 ). No significant changes in mean arterial pressure or heart rate were observed during or immediately after the LHM. However, we observed a significant increase in peripheral oxygen saturation after LHM (Table 2). No significant changes in respiratory pattern (tidal volume and respiratory rate) were observed.

As shown in Figure 1, LHM induced a significant increase in 2-h plasma concentration of all measured cytokines, with a return to baseline levels $12 \mathrm{~h}$ later. A close correlation was observed between the LHM-induced increase in inflammatory (IL-6) and anti-inflammatory (IL-10) cytokines, as shown in Figure 2. Clinical examination after the procedure did not detect harmful events. Neither pneumothorax nor other extra-alveolar air leaks were observed in control chest X-ray plates.

\section{Discussion}

We observed that the application of an LHM (inspiratory pressure of $40 \mathrm{cmH}_{2} \mathrm{O}$ for a short period of time) by noninvasive ventilation increased both inflammatory and anti-inflammatory cytokines in spontaneously breathing healthy subjects. To our knowledge, this is the first study showing, that under these conditions, that LHM elicits a systemic inflammatory response independently of underly- 
ing pulmonary disease or mechanical ventilation.

Several publications have reported beneficial effects of LHM on reopening of atelectatic lung regions, improving oxygenation and pulmonary compliance during general anesthesia and in acute respiratory failure, either in experimental or clinical settings $(6,16-21)$. However, stretching the lung parenchyma beyond its physiological limits using high airway inspiratory pressures is associated with an over-distention-induced inflammatory response.

In this study, we observed that an LHM applied for a short period of time (up to 1 to $2 \mathrm{~min}$ ) to normal homogeneously aerated lungs induced a slight but significant increase in plasma pro- and anti-inflammatory cytokines, with a return to baseline levels within $12 \mathrm{~h}$. Apart from the LHM, none of the healthy subjects participating in this study had active or chronic inflammatory conditions that could explain the release of plasma cytokines. After performing the maneuver, subjects remained in relative rest during the following $12 \mathrm{~h}$ in order to avoid any further inflammatory stimuli.

Lung parenchyma stretch can modify the gene ex-
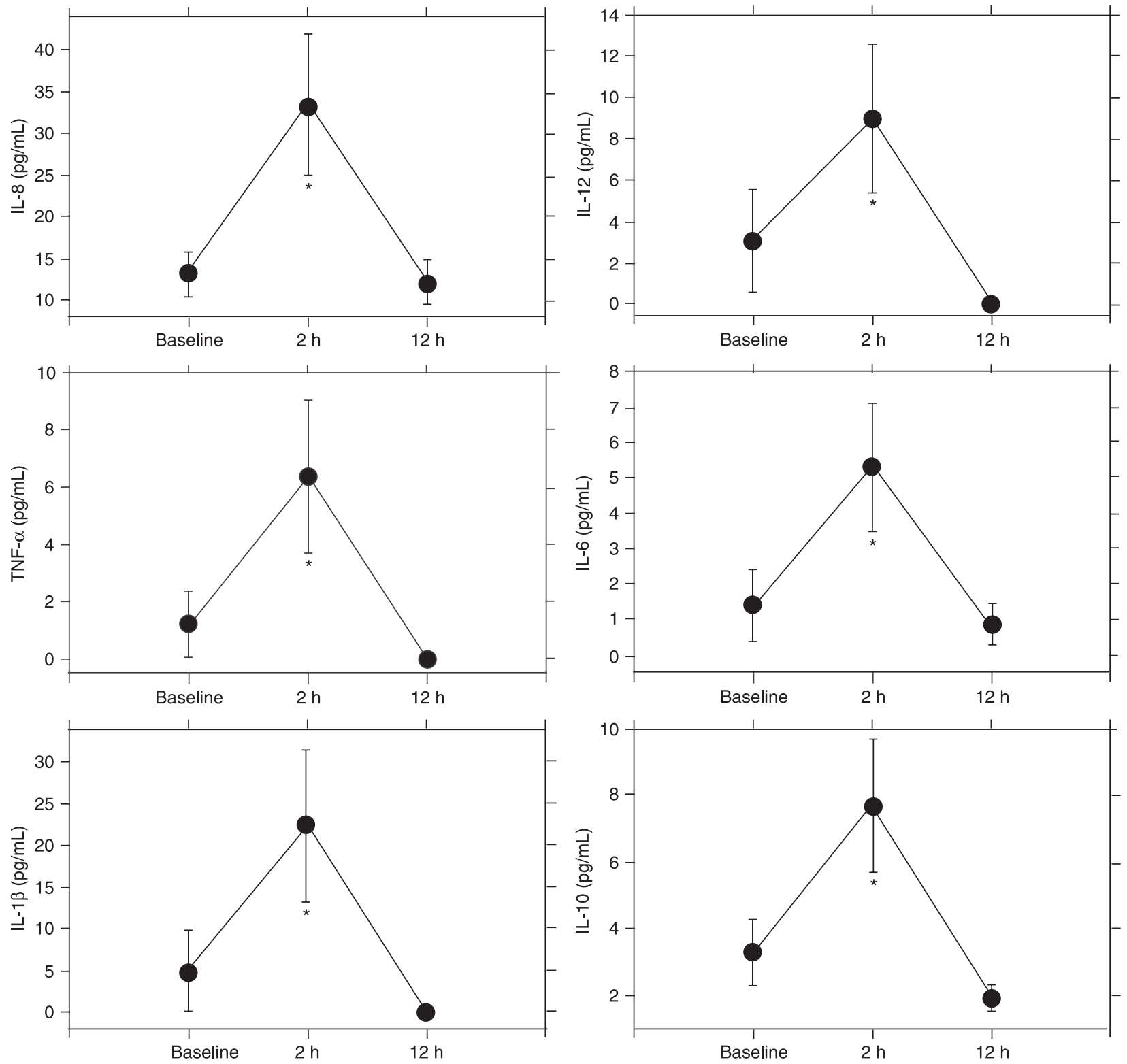

Figure 1. Plasma cytokine (TNF- $\alpha$, IL-1 $\beta$, IL-6, IL-8, IL-10, IL-12) levels. * $\mathrm{P}<0.05$ compared to baseline value for each cytokine (oneway ANOVA for repeated measures followed by the Student-Newman-Keuls test). 


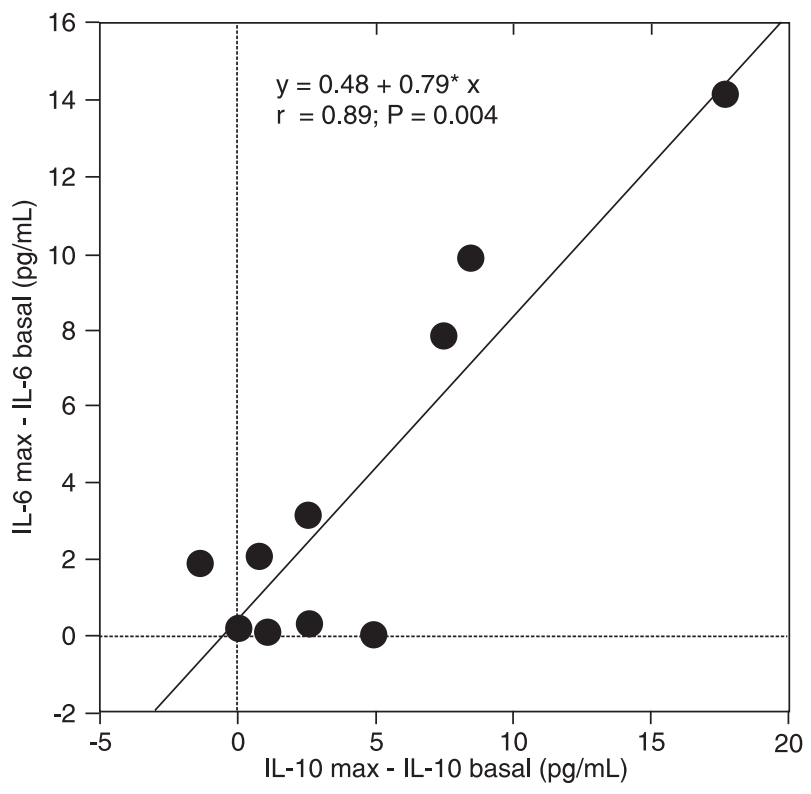

Figure 2. Linear regression between the lung hyperinflation maneuver-induced increase in IL- 6 and IL-10. Correlation tested by Pearson product-moment correlation coefficient.

pression of several inflammatory and anti-inflammatory molecules in the lung (22), which may ultimately lead to an inflammatory process. Vlahakis et al. (23) detected in vitro IL-8 release from alveolar epithelial type II cells stretched by $30 \%$ for up to $48 \mathrm{~h}$. Wilson et al. (12) have shown that high-stretch ventilation by applying high tidal volumes induces intrapulmonary TNF- $\alpha$ and macrophage-inflammatory protein-2 (MIP-2) expression in previously healthy mice. Moriondo et al. (24) showed that mechanical ventilation could markedly damage the extracellular matrix in previously healthy rats in a tidal volume-dependent fashion. Mascheroni et al. (25) reported extensive lung injury after intense hyperventilation and increased transpulmonary pressures in spontaneously breathing previously healthy sheeps. Ranieri et al. (13) have shown that mechanical ventilation of patients with acute respiratory failure could induce a cytokine response that may be attenuated by a strategy to minimize over-distention and recruitment/derecruitment of the lungs. More recently, Terragni et al. (26) showed that airway pressures up to $30 \mathrm{cmH}_{2} \mathrm{O}$ might induce a marked inflammatory response in patients with acute lung injury/acute respiratory distress syndrome during invasive

\section{References}

1. Gale GD, Teasdale SJ, Sanders DE, Bradwell PJ, Russell A, Solaric B, et al. Pulmonary atelectasis and other respiratory complications after cardiopulmonary bypass and investigation of aetiological factors. Can Anaesth Soc J 1979; 26: 15-21. mechanical ventilation.

Evidence to the contrary has been published by Puls et al. (27), who did not find any release of inflammatory mediators after LHM using $40 \mathrm{cmH}_{2} \mathrm{O}$ CPAP for $7 \mathrm{~s}$ in patients with acute respiratory failure in different stages of their diseases. Since most of their patients were recruited relatively late in the course of their disease, and did not show any increase in $\mathrm{PaO}_{2}$ until $180 \mathrm{~min}$, the pressure and the length of airway pressurization during LHM may not have been enough to open collapsed small airways and alveoli.

Interestingly, we found a close correlation between inflammatory and anti-inflammatory cytokines. Thus, we hypothesize that, at least in healthy subjects, the acute stretch of the lung parenchyma on the one hand stimulates the release of inflammatory cytokines, but on the other hand this effect is, at least in part, balanced by a subsequent increase in anti-inflammatory cytokines. It is possible that such a phenomenon is the physiological response to parenchymal stretch in normal conditions. Since a single LHM was applied during the study and subjects were not submitted to any stressful physiological stimuli, pro- and anti-inflammatory cytokines returned to baseline values within $12 \mathrm{~h}$. However, the magnitude of increase in cytokines was not great enough to allow us to support the notion that the inflammatory response triggered by a single lung hyperinflation maneuver may damage the lungs, especially if weighed against the beneficial effects of LHM on lung collapse. On the other hand, it remains to be determined if the repeated use of such maneuvers can be detrimental in subjects with normal lungs.

Since a single LHM was performed in our study, our data cannot be generalized to other maneuvers using different airway pressures and pressurization time length. Since we applied both an increase in positive end-expiratory pressure and delta inspiratory pressure, we are unable to determine if the effects were mainly due to stress or strain or to their combination. The study was conducted on healthy subjects during spontaneous breathing in the absence of sedation or invasive mechanical ventilation and the data cannot be directly extrapolated to clinical conditions of diseased lungs that are being ventilated using elevated airway pressures.

\section{Acknowledgments}

Research supported by FAPESP (\#2006/57786-2).
2. Moller JT, Johannessen NW, Berg H, Espersen K, Larsen LE. Hypoxaemia during anaesthesia - an observer study. $\mathrm{Br}$ J Anaesth 1991; 66: 437-444.

3. Lundquist $H$, Hedenstierna $G$, Strandberg A, Tokics L, Brismar B. CT-assessment of dependent lung densities in 
man during general anaesthesia. Acta Radiol 1995; 36: 626632.

4. Tokics L, Hedenstierna G, Strandberg A, Brismar B, Lundquist $\mathrm{H}$. Lung collapse and gas exchange during general anesthesia: effects of spontaneous breathing, muscle paralysis, and positive end-expiratory pressure. Anesthesiology 1987; 66: 157-167.

5. Rothen HU, Sporre B, Engberg G, Wegenius G, Hedenstierna G. Re-expansion of atelectasis during general anaesthesia: a computed tomography study. Br J Anaesth 1993; 71: 788-795

6. Rothen HU, Neumann P, Berglund JE, Valtysson J, Magnusson A, Hedenstierna G. Dynamics of re-expansion of atelectasis during general anaesthesia. Br J Anaesth 1999; 82: $551-556$.

7. Tusman G, Bohm SH, Suarez-Sipmann F, Turchetto E. Alveolar recruitment improves ventilatory efficiency of the lungs during anesthesia. Can J Anaesth 2004; 51: 723-727.

8. Claxton BA, Morgan P, McKeague H, Mulpur A, Berridge J. Alveolar recruitment strategy improves arterial oxygenation after cardiopulmonary bypass. Anaesthesia 2003; 58: 111116.

9. Tremblay L, Valenza F, Ribeiro SP, Li J, Slutsky AS. Injurious ventilatory strategies increase cytokines and c-fos m-RNA expression in an isolated rat lung model. J Clin Invest 1997; 99: 944-952.

10. Chiumello D, Pristine G, Slutsky AS. Mechanical ventilation affects local and systemic cytokines in an animal model of acute respiratory distress syndrome. Am J Respir Crit Care Med 1999; 160: 109-116.

11. Wilson MR, Choudhury S, Takata M. Pulmonary inflammation induced by high-stretch ventilation is mediated by tumor necrosis factor signaling in mice. Am J Physiol Lung Cell Mol Physiol 2005; 288: L599-L607.

12. Wilson MR, Choudhury S, Goddard ME, O'Dea KP, Nicholson AG, Takata M. High tidal volume upregulates intrapulmonary cytokines in an in vivo mouse model of ventilatorinduced lung injury. J Appl Physiol 2003; 95: 1385-1393.

13. Ranieri VM, Suter PM, Tortorella C, De Tullio R, Dayer JM, Brienza A, et al. Effect of mechanical ventilation on inflammatory mediators in patients with acute respiratory distress syndrome: a randomized controlled trial. JAMA 1999; 282: 54-61.

14. Bueno PC, Bueno CE, Santos ML, Oliveira-Junior I, Salomao R, Pinheiro BV, et al. Ventilation with high tidal volume induces inflammatory lung injury. Braz J Med Biol Res 2002; 35: 191-198.

15. Zupancich E, Paparella D, Turani F, Munch C, Rossi A, Massaccesi S, et al. Mechanical ventilation affects inflammatory mediators in patients undergoing cardiopulmonary bypass for cardiac surgery: a randomized clinical trial. $J$ Thorac Cardiovasc Surg 2005; 130: 378-383.

16. Bendixen HH, Hedley-White J, Laver MB. Impaired oxygenation in surgical patients during general anesthesia with controlled ventilation. A concept of atelectasis. N Engl J Med 1963; 269: 991-996.

17. Tenling A, Hachenberg T, Tyden H, Wegenius G, Hedenstierna $\mathrm{G}$. Atelectasis and gas exchange after cardiac surgery. Anesthesiology 1998; 89: 371-378.

18. Amato MB, Barbas CS, Medeiros DM, Magaldi RB, Schettino GP, Lorenzi-Filho G, et al. Effect of a protective-ventilation strategy on mortality in the acute respiratory distress syndrome. N Engl J Med 1998; 338: 347-354.

19. Borges JB, Okamoto VN, Matos GF, Caramez MP, Arantes PR, Barros F, et al. Reversibility of lung collapse and hypoxemia in early acute respiratory distress syndrome. $A m \mathrm{~J}$ Respir Crit Care Med 2006; 174: 268-278.

20. Magnusson L, Zemgulis V, Tenling A, Wernlund J, Tyden H, Thelin S, et al. Use of a vital capacity maneuver to prevent atelectasis after cardiopulmonary bypass: an experimental study. Anesthesiology 1998; 88: 134-142.

21. Bond DM, Froese AB. Volume recruitment maneuvers are less deleterious than persistent low lung volumes in the atelectasis-prone rabbit lung during high-frequency oscillation. Crit Care Med 1993; 21: 402-412.

22. Copland IB, Kavanagh BP, Engelberts D, McKerlie C, Belik $\mathrm{J}$, Post M. Early changes in lung gene expression due to high tidal volume. Am J Respir Crit Care Med 2003; 168: 1051-1059.

23. Vlahakis NE, Schroeder MA, Limper AH, Hubmayr RD. Stretch induces cytokine release by alveolar epithelial cells in vitro. Am J Physiol 1999; 277: L167-L173.

24. Moriondo A, Pelosi P, Passi A, Viola M, Marcozzi C, Severgnini $P$, et al. Proteoglycan fragmentation and respiratory mechanics in mechanically ventilated healthy rats. $J$ Appl Physiol 2007; 103: 747-756.

25. Mascheroni D, Kolobow T, Fumagalli R, Moretti MP, Chen $\mathrm{V}$, Buckhold $\mathrm{D}$. Acute respiratory failure following pharmacologically induced hyperventilation: an experimental animal study. Intensive Care Med 1988; 15: 8-14.

26. Terragni PP, Rosboch G, Tealdi A, Corno E, Menaldo E, Davini $O$, et al. Tidal hyperinflation during low tidal volume ventilation in acute respiratory distress syndrome. Am J Respir Crit Care Med 2007; 175: 160-166.

27. Puls A, Pollok-Kopp B, Wrigge H, Quintel M, Neumann P. Effects of a single-lung recruitment maneuver on the systemic release of inflammatory mediators. Intensive Care Med 2006; 32: 1080-1085. 